\title{
1 Thought Experiments, Justice and Character
}

Thought experiments are of extended use in current debates about ethical and meta-ethical issues. In exploring such experiments, scholars engage in endless sequences of examples and counterexamples, where references to classic literary works, paintings or movies do not abound; psychological or sociological experiments are also rarely mentioned, except in the context of some specific debates. ${ }^{1}$ Examples in such thought experiments are generally sketched with two or three strokes where only a few features are mentioned. It is scarcely noticed, however, that by characterizing a situation in one way or another, we may be introducing a serious bias into the discussion. ${ }^{2}$ And, yet, a significant number of philosophers seem to assume that the study of thought experiments in light of a series of sketchy examples (and counterexamples) constitutes the best means to advance the philosophical debate. They seem to be convinced that, by persisting in this procedure, the essential features of our ethical practices will ultimately be apprehended and also the moral principles that lie at the core of a meaningful life. It is not my purpose to deny that thought experiments must play a role in philosophical reflection on moral issues, but to stress the need to complement this methodological resource with other means of understanding that may help us to discern the moral demands we may eventually confront. For, otherwise, one may unknowingly project onto the thought experiment itself a rather elementary comprehension of our moral practices, which may thereby seem confirmed.

Motivations of various sorts have encouraged the use of thought experiments as the main methodological resource in the examination of ethical and meta-ethical issues. ${ }^{3}$ Some of them are associated with a conception of practical rationality that emphasizes the relevance of principles and abstraction in our ability to lead a moral life. Such a conception is, indeed, central to the Kantian approach and also to a thought experiment of some significance in that tradition, namely, John Rawls' original position. In this chapter, I plan to challenge the privileged function that Rawls ascribes to this thought experiment in his conception of political justice. Deliberation in the original position is supposed to abstract away from any specific features of character and, therefore, from any particular moral situations that 
one may actually have faced, since these are purely circumstantial elements to be discarded as both irrelevant and misleading for a proper deliberation on the principles of justice. The virtues of this deliberative procedure will be put in doubt when viewed from the perspective of a particular moral experience, namely, the shame that Primo Levi (as well as many other survivors) suffered after liberation from Auschwitz.

This challenge will in turn favor a certain style of philosophical reflection, ${ }^{4}$ a manifest feature of which will be that the study of particular, full-fledged experiences must permeate our philosophical reflection on the experience of harm and the kind of response that it may legitimately demand from us. ${ }^{5}$ The overall idea is that moral concepts cannot really be dissociated from the way we actually respond to some particular moral experiences, and how we actually project them onto other cases. For, ultimately, there are no other means of identifying the relevant similarity relations but through our actual practices of projection; as a result, the role of concepts and principles will not so much be to fix a content that may be exemplified in multiple cases, but to guide us through those practices of projection. ${ }^{6}$ This is why I will only exceptionally provide general, abstract characterizations of the conceptual distinctions I may eventually introduce. For, otherwise, the style itself might suggest that our understanding of the different views and conceptual distinctions can actually be detached from the experiences and situations that may have inspired them in the first place. I will thus try to associate any abstract distinctions and considerations with those particular issues and situations that may give rise to them. Still, if my analysis of the experience of harm is vaguely correct, stylistic maneuvers of this sort will turn out to be rather ineffective on some crucial occasions, given the power of some contrary psychological mechanisms.

Finally, let me mention that the study of Levi's shame will serve to anticipate a number of substantive points to be developed and refined in the chapters to come. The moral significance of the asymmetries between the first-person and the third-person perspectives will thus be defended, as well as the need to revise the assumption that moral deliberation is necessarily distorted by one's emotional attachments and favored instead by a detached view of the facts. I will derivatively stress the indispensability of a certain kind of necessity in moral deliberation. This sort of necessity may at first sound hard to accept insofar as it is alien both to rational necessity as it is conceived of within the Kantian approach, and to the sort of blind necessity to which our desires and natural dispositions are supposedly subject. The issue as to whether there is room for this alternative kind of necessity and how it may affect the way the Kantian approach construes the other two will be especially examined in Chapter 6 . The present chapter will close, in any case, with a sketch of the Kantian approach as I see it, which is to be distinguished from Kant's view insofar as that approach is meant to articulate a framework of distinctions and claims that lies behind a number of 
different philosophical views and also permeates the common understanding of our moral practices.

\subsection{JOHN RAWLS: THE ORIGINAL POSITION}

The original position is initially presented as a device of representation, as a thought experiment, designed to determine the fundamental principles of justice for the basic structure of society (Rawls 1999: 10-12, 506; 2001a: xvii; 2005: xviii). All this requires the assumption that we are dealing with a stable society "divided by reasonable though incompatible religious, political, and moral doctrines" (Rawls 2005: xviii). For it is this kind of society that gives rise to the problem of political liberalism, namely, of how it is possible that in such circumstances "there may exist over time a stable and just society of free and equal citizens" (Rawls 2005: xviii). From this perspective, the plurality of reasonable comprehensive doctrines is not regarded so much as a regrettable accident, but as "the normal result of the exercise of human reason within the framework of the free institutions of a constitutional democratic regime" (Rawls 2005: xvii).

The principles that the original position may eventually deliver, as well as the particular judgments that may follow from them, must meet the demands of reflective equilibrium, that is, they must match "our considered judgments once they have been pruned and adjusted" (Rawls 1999: 18. See Goodman 1983: 63-4). There is, however, a distinction Rawls does not explicitly mention but seems essential to his project, namely, the distinction between

A Hypothetical C-Judgment: An agent's considered judgment about a particular moral situation $\mathrm{S}$, such that she has not actually faced either $S$ itself or any other particular situation $S^{*}$ relevantly similar to $S$,

and

An Actual C-Judgment: An agent's considered judgment about a particular moral situation $\mathrm{S}$ once she has actually faced $\mathrm{S}$ or some other particular situation $S^{*}$ relevantly similar to $S$,

where 'c-judgment' stands for 'considered judgment'. The first kind of judgment may be regarded as hypothetical insofar as the agent is not evaluating a situation $S$ she has actually experienced, but a situation that she (or someone else) might eventually face; by contrast, the second kind of judgment appears as actual insofar as the agent is (or has been) faced with the situation (or a relevantly similar one) that she is trying to assess. In view of this distinction, the sorts of judgments that the original position might deliver will certainly qualify as hypothetical, even though of a specific kind. 
In any case, it seems clear that, if the original position is to pass the reflective equilibrium test, the following assumption must be made:

If agents deliberate flawlessly, there will be no mismatch between their hypothetical c-judgments and their actual c-judgments.

For, otherwise, there would be no reason to think that our judgments in the original position will be able to reasonably track both our hypothetical c-judgments and our actual c-judgments, as reflective equilibrium seems to demand. I will argue, however, that there are some cases of mismatch that a certain kind of flaw cannot explain away, namely, a flaw that agents could reasonably be expected to overcome from within their own respective stances, either hypothetical or actual. Moreover, I defend the view that in some such cases it is the actual c-judgment that must prevail. Trivially, this line of reasoning does not call into question the previous assumption as it stands, since one or another sort of deliberative mistake will still be involved in the cases of mismatch I intend to highlight. There is, however, a stronger assumption that the original position must grant, namely:

The Matching Assumption: if agents deliberate in such a way that they make no mistake that could reasonably have been prevented from within their respective deliberative stances (either hypothetical or actual), there is no room for a mismatch between their hypothetical c-judgments and their actual c-judgments.

Still, I will argue that, insofar as the original position is to be construed as a device of representation, the modality of 'could' must be constrained in such a way that the Matching Assumption turns out to be false. To develop my case, I will mainly rely on Primo Levi's description of his experience of shame as a survivor of Auschwitz in his last book, The Drowned and the Saved (Levi 1986). More specifically, I will focus on his experience of shame to conclude that his actual c-judgments on that experience must prevail over what would have been his hypothetical c-judgment about it, and also that this mismatch could not reasonably have been surmounted by further hypothetical deliberation. This will put the Matching Assumption under some pressure, as we shall see, and consequently invite the thought that the deliverances of the original position may not always prevail over an agent's actual c-judgments. Of course, one could doubt the relevance of Levi's c-judgments themselves: firstly, because a reflection on shame is apparently foreign to issues in political justice and, secondly, because it is unclear why Levi's views on shame should be particularly authoritative. I will address the first worry in due course but, regarding the second, let me just mention that The Drowned and the Saved is usually regarded as a central contribution to our understanding of the survivor's experience. Hence, 
it seems that his considered judgment on this matter has thoroughly been recognized as particularly significant and, consequently, any relevant worries about any given judgment of his ought to be grounded on some specific reasons and not on the overall idea that he could be wrong; for, otherwise, the demand that the original position must pass the reflective equilibrium test would become empty. ${ }^{7}$ Let's now have a look at the details.

\subsubsection{Reasoning behind the Veil of Ignorance}

Rawls proposes the original position as "an expository device" (Rawls 1999: 19; see 2005: 28, 75), as "a device of representation or, alternatively, a thought-experiment for the purpose of public- and self-clarification" (Rawls 2001a: 17. See 2005: 9, 45-6) that may help us to establish the principles of justice in a society. It is clear, however, that this might serve that purpose only insofar as it may appropriately model our convictions about "fair conditions of agreement between citizens as free and equal" (Rawls 2001a: 17 . See 2005: $8-9,28,45-6,119)$ by placing some constraints as to the kind of reasons that can legitimately be provided in that context (Rawls 2002: 129-80; 2005: xix, 9).

The original position is not to be construed as a historical situation, but as a bypothetical one where agents are asked to deliberate, under certain conditions $\mathrm{O}$, about the principles that must articulate the basic structure of society, that is, its main political and social institutions (Rawls 1999: 11, 14; 2001a: 10, 16; 2005: 11, 28, 274). In so doing, agents hypothesize about the principles of justice upon which everyone in those conditions would agree. What are, though, conditions $\mathrm{O}$ and how are agents supposed to hypothesize? People under conditions $\mathrm{O}$ are supposed

(1) to deliberate behind a veil of ignorance, which involves: (a) lack of knowledge about one's place in society and one's specific biological endowment; but also (b) lack of knowledge about one's own conception of the good (Rawls 1999: 11; 2001a: 15, 18; 2005: 23-6).

(2) to be equal in three respects: (a) they are rational, that is, they are able to choose "the most effective means to given ends" (Rawls 1999: 12. See 1999: 124; 2005: 25, 49-55); (b) they should count on two moral powers: (i) the capacity for a sense of justice, which ensures that the principles agreed upon will be honored (Rawls 1999: 125; 2001a: 18-9; 2005: 19); (ii) the capacity for a conception of the good, even though agents must indeed abstract away in their deliberations from the specific conception of the good that they may respectively endorse (Rawls 2001a: 19; 2005: 19); and (c) they all have the same rights in the procedure by means of which the principles of justice are to be determined (Rawls 1999: 17; 2005: 52-3). 
Deliberation behind the veil of ignorance is fundamentally deductive or rational; ${ }^{8}$ and this political geometry applies both to the determination of the principles of justice and the transition from such principles to those particular judgments that they may eventually support. ${ }^{9}$ We may thus characterize the sort of particular judgments that may be deductively justified in the original position as follows:

An Original C-Judgment: An agent's judgment under conditions O about what judgment regarding a particular situation $S$ everyone under such conditions would ultimately agree upon insofar as issues of political justice are concerned.

Some might object that my characterization of the sort of deliberation that agents behind the veil of ignorance are supposed to engage in owes too much to A Theory of Justice (Rawls 1999) and neglects the central role that the distinction between the rational and the reasonable plays in Rawls' later writings (Rawls 2005: 48-9). But, firstly, these two notions are presented as complementary in such writings and, secondly, Rawls stresses that reasonableness is guaranteed by the conditions under which agents are to deliberate in the original position, ${ }^{10}$ but does not play any significant role in a deliberation under such conditions, which is claimed to be merely constrained by the rational and, in this respect, fundamentally deductive:

Political constructivism is a view about the structure and content of a political conception. It says that once, if ever, reflective equilibrium is attained, the principles of political justice (content) may be represented as the outcome of a certain procedure of construction . . . In this procedure, as modeled by the original position, rational agents, as representatives of citizens and subject to reasonable conditions, select the public principles of justice to regulate the basic structure of society. (Rawls 2005: 89-90)

Be that as it may, it is clear that original c-judgments are hypothetical. For agents in the original position are assumed to deliberate behind the veil of ignorance, whereby they must, among other things, abstract away from the fact that they may have actually faced one or another particular situation. Moreover, it is important to stress that, even though deliberation in the original position may be regarded as merely deductive, the match between our original c-judgments and our actual c-judgments cannot be deductively guaranteed. For such a match concerns the ability of the original position to pass the reflective equilibrium test, and the satisfaction of this constraint is a fact agents under conditions $\mathrm{O}$ cannot deductively infer. To put it another way, even though the original position is to be construed as a sort of deductive device where agents deliberate behind the veil of ignorance and see what can be deduced about the principles of justice under such conditions, 
the question remains as to whether the principles that may thus be deduced do match "our considered judgments duly pruned and adjusted" (Rawls 1999: 18).

Moreover, the original position is introduced as an actual device to determine the principles of justice in a society, whereby some specifications are needed regarding its operating conditions. Following up from Wittgenstein, we may distinguish between a device as a mere set of instructions and a device as an actual mechanism that can be used by some people in normal circumstances (Wittgenstein 1953: $\$ 193-96$ ). Wittgenstein was convinced that, in the end, both senses collapse into one insofar as the content of a set of instructions is parasitic upon the way the mechanism is actually used by normal agents. " This is not a claim I intend to discuss here, though; for I would like to defend a weaker claim, namely, that inasmuch as the original position is to be construed as a real device, it cannot deliver the appropriate results. Yet, if it were interpreted instead as a mere set of instructions with no specific constraint concerning the conditions under which an agent might be able to follow them, the original position would have no particular claim to make over many other sets of instructions, and therefore could hardly be vindicated as a device that may pass the reflective equilibrium test in a relevant and non-empty way.

Let us then assume that the original position is an actual device that human agents may reasonably be expected to employ. Some constraints seem to follow then. One such constraint is that conditions $\mathrm{O}$ cannot be intelligibly conceived of as a set of conditions under which human agents may actually place themselves. For there is a conceptual tension between identifying someone as an adult human agent and claiming, for instance, that they do not know anything at all about their specific biological endowment, about their particular conception of the good or about their actual social condition. This provides a relevant sense in which the original position is necessarily hypothetical. And, in this respect, the original position does not require agents to actually be ignorant of some trivial facts about themselves, but only that they should abstract away from what they actually know about themselves, since any such piece of knowledge might eventually interfere with their deliberation about what ought to be acknowledged as just. Rawls seems to be convinced that this departure from the details of one's condition is not only possible, but beneficial. ${ }^{12}$ Yet, we can only recognize such a procedure as possible insofar as the deliberative capacities involved are sufficiently encapsulated, so that they may operate independently of any specific trait in the agent's character, which would thereby be regarded as deprived of any deliberative import and, from this perspective, as purely idiosyncratic. And this procedure can also be perceived as beneficial for a concomitant reason: if we have the ability to deliberate regardless of our character, we better take advantage of it and detach ourselves from any trait of it that might contaminate our judgment. Such a detachment seems to be indispensable to honor the call for impartiality commonly 
associated with moral deliberation, but it is even more so whenever matters of social and political justice are concerned. All this suggests a specific conception of the ways in which our deliberative capacities may relate to other aspects of our psychology, even though it is clear that Rawls would like the original position (and, in general, his conception of political justice) to be as independent as possible of any specific conception of the self. And, with regard to those metaphysical commitments that may nevertheless remain, the hope is that they will at least be compatible with a sound philosophical or psychological conception of the self (Rawls 2001a: 19; 2005: 27-35), but little is said to justify these positive expectations. In fact, my challenge to the Matching Assumption and the corresponding vindication of the deliberative significance of our actual c-judgments in matters of political justice will cast doubt on the encapsulated conception of rationality and the associated view of the self that the original position seems to presuppose, even though a detailed discussion of these issues will only develop in Chapters 4 to 6 .

\subsubsection{The Demands of Reflective Equilibrium}

There are not, according to Rawls, any facts of the matter that might be independent of our considered convictions about justice, such that a satisfactory conception of political justice ought to track. He thereby departs from moral realism ('rational intuitionism' as he calls it (Rawls 2005: 91-2)) to endorse a constructivist view that is supposed to be constrained by our considered convictions at one or another level of generality. In other words, the search for reflective equilibrium between our considered convictions and the principles that may articulate a certain conception of political justice is the only means by which any such conception is to be ultimately justified or instead challenged.

The original position was thus presented as a device of representation in virtue of which some principles of justice are delivered and such that they are meant to organize "our familiar ideas and principles into a conception of political justice that expresses those ideas and principles in a somewhat different way than before" (Rawls 2005: 9). It is clear, by now, that the original position could only shed a new light on our considered convictions of justice if it might pass the reflective equilibrium test, that is, if the principles and particular judgments that it may generate matched our "considered judgments once they have been pruned and adjusted"(Rawls 1999: 18). Once this constraint were met, no further requirement would be in the offing; but only insofar as it is met could the original position be recognized as a suitable device to determine the principles of justice for the basic structure of society:

It [the original position] represents the attempt to accommodate within one scheme both reasonable philosophical conditions on principles as well as our considered judgments of justice . . . I do not claim for the 
principles of justice proposed that they are necessary truths or derivable from such truths. A conception of justice cannot be deduced from self-evident premises or conceptions on principles; instead, its justification is a matter of the mutual support of many considerations, of everything fitting together into one coherent view. (Rawls 1999: 19. See 2001a: 29-32)

Yet, if the demand for reflective equilibrium is to be properly applied, means must be specified to individuate our considered judgments and convictions, such that they are reasonably independent of the fact that any such judgment could actually be inferred from the principles that might be agreed upon in the original position (Rawls 1999: 42; 2005: 77). This requirement, trivial as it is, will play an important role in my case against the relevance of the original position as a suitable device of representation.

Rawls' scarce remarks on this issue point to those judgments or convictions that, being firm and stable, have been acquired in the appropriate deliberative circumstances, which are in turn individuated by the fact that "the more common excuses and explanations do not obtain":

Considered judgments are simply those rendered under conditions favorable to the exercise of the sense of justice, and therefore in circumstances where the more common excuses and explanations for making a mistake do not obtain. The person making the judgment is presumed, then, to have the ability, the opportunity, and the desire to reach a correct decision (or at least, not the desire not to). Moreover, the criteria that identify these judgments are not arbitrary. They are, in fact, similar to those that single out considered judgments of any kind. And once we regard the sense of justice as a mental capacity, as involving the exercise of thought, the relevant judgments are those given under conditions favorable for deliberation and judgment in general. (Rawls 1999: 42)

There may be several reasons why the judgments of people who are not subject to misleading circumstances (or prey to the more common excuses) may, nevertheless, diverge, and this fact may eventually damage the ability of the original position to pass the reflective equilibrium test. There is one such divergence whose inescapability I would like to stress, though. It has to do with the mismatch between an agent's c-judgment regarding a particular case $S$ whenever she may not have yet experienced that situation (or a relevantly similar one), and her c-judgment whenever she may have actually faced it (or a relevantly similar one). ${ }^{13}$ Insofar as any such mismatch has to do with the particular situations a given agent may have actually encountered, Rawls might easily reply that the relevance of this kind of experience for the original position has already been excluded. For the peculiar circumstances of each particular agent are of no avail to a sort of deliberation 
that must proceed behind the veil of ignorance. The issue arises, however, as to whether the judgments delivered in the original position may actually match our actual c-judgment in the absence of any relevant mistake. A mismatch between these two sorts of judgments may reveal a failure in deliberation, but not necessarily of the relevant kind. For, insofar as the original position is to be conceived of as an actual device of deliberation, we can only rely on the absence of those flaws that agents could reasonably be expected to overcome from within their respective stances, either actual or hypothetical. Hence, I will examine some cases of mismatch between our original c-judgments and our actual c-judgments in order to see whether they may reasonably be explained away by a deliberative flaw that could thus be surmounted, as the Matching Assumption explicitly demands.

There is a significant distinction as to the individuation of our considered judgments that Rawls hardly mentions, but seems to be constitutive of the very idea of reflexive equilibrium, namely, the distinction between those judgments that our practices actually express and those judgments on the principles and convictions that guide our practices that competent practitioners may, after proper reflection, explicitly endorse (Goodman 1983: 62-3). This distinction somewhat parallels the contrast between knowing how to speak a language and knowing that such and such rules guide our linguistic practice (Ryle 2008: ch. 2). It follows that, in order to determine our considered judgments on a certain matter, we must not only take account of people's explicit endorsements and declarations, but also examine their actual practices and discern what principles and convictions may thereby be expressed. For the content of our considered judgments may be fixed differently depending on how it is elucidated and, consequently, the issue will arise as to whether it is what we express or what we endorse that must prevail or something in between. ${ }^{14}$ An approach to our considered judgments that makes room for a closely related kind of divergence is the study of those works that are regarded as classics. In short, we may say that a certain object (a text, a painting, a piece of music and so on) is thus identified insofar as it is regarded as an endless source of reflection and, therefore, as a continuous invitation to renew our views and practices on certain matters. It is constitutive of this attitude toward, say, a text that there will always be room for further elucidation of what is actually being expressed and defended within it. We must not then assume that the final significance of a classic text, like that of our practices, could ever be fully apprehended. On this basis, I propose to examine Primo Levi's last book, The Drowned and the Saved (Levi 1986), which may reasonably be presented as a classic regarding the survivor's experience. More specifically, I will explore his reflections on the sort of shame that he (like many other survivors) unexpectedly suffered after his liberation, and stress how some aspects of his experience cast doubt on the Matching Assumption and, derivatively, challenge the prevalent use of thought experiments (and sketchy examples) in ethical and meta-ethical investigations. 


\subsection{PRIMO LEVI'S SHAME}

\subsubsection{Stereotypical Expectations}

In the third chapter of The Drowned and the Saved (1986), Levi puts forward his maturest view on his experience of shame. To begin with, he highlights the mismatch between his view about liberation while he was still imprisoned in Auschwitz (say, time $\mathrm{T}_{0}$ ) and after his liberation (say, time $T_{1}$ ). At time $T_{0}$, Levi was convinced that, if he survived, he would have nothing to feel ashamed of or guilty for. And it was on this assumption that he expected his life after liberation to be lighthearted and joyful. It happened though that, at time $T_{1}$ and despite this promising expectations, he was haunted by deep anguish which he finally recognized as springing from a sense of shame for what he actually did or fell short of doing in the extermination camp:

That many (and myself) experienced 'shame', that is, a feeling of guilt during the imprisonment and afterwards is an ascertained fact confirmed by numerous testimonies. It may seem absurd, but it does exist. I will try to interpret it myself, and to comment on the interpretations of others. (Levi 1986: 54)

The mismatch between Levi's expectations and his actual experience may seem, at first sight, quite irrelevant to a theory of political justice insofar as it may sound like just another case in which reality does not meet one's expectations. Yet, even though the discomfort which gave rise to the mismatch was at the outset merely experienced as anguish, it was later on discovered to involve a moral self-reproach and, thereby, some room seems to have been made for moral considerations. In any case, some people might still reply that the mismatch in question is not at all relevant to the debate about the original position insofar as it can hardly be identified as a mismatch between two considered moral judgments. For, given the survival conditions in the extermination camp, Levi's judgment at $T_{0}$ could hardly be presented as such. In fact, Levi himself stresses that his promising expectations derived from a stereotypical view about liberation that he (like many others) had inadvertently internalized. And it seems quite reasonable to assume that stereotyped judgments do not at all qualify as considered, even though later considerations in this essay may induce us to renounce this conviction: ${ }^{15}$

There exists a stereotyped picture, proposed innumerable times, consecrated by literature and poetry and picked up by the cinema; at the end of the storm, when 'the quiet after the storm' arrives, all hearts rejoice. 'To be freed from pain is delightful for us'. After the disease, health returns; to deliver us from imprisonment 'our boys' arrive just in time, 
the liberators, with waving flags; the soldier returns and again finds his family and peace. (Levi 1986: 52)

Levi's reflection at $T_{1}$ surely constitutes an attempt to go beyond the stereotype in order to uncover his genuine experience, for, otherwise, "convention prevails over genuine memory" (Levi 1986: 53). The upshot of this reflection may thus be taken as a considered judgment about the moral significance of his shame, but it is still clear that Levi's judgment at $\mathrm{T}_{0}$ can hardly count as such. What could then be the relevance of Levi's experience for the Matching Assumption and, in the end, for the original position if no conflict between considered judgments has so far been detected? Further aspects of Levi's experience need then to be examined in order to make my case against the original position. But for now, let us take advantage of the previous distinctions and considerations to state the three main theses I intend to defend:

(T1) There is room for relevantly flawless mismatches between our hypothetical c-judgments and our actual c-judgments and, derivatively, between the latter and our original c-judgments.

(T2) In some relevant cases of flawless mismatch, our actual c-judgments must prevail.

(T3) Cultural stereotypes may severely distort our hypothetical c-judgments. ${ }^{16}$

\subsubsection{Is Levi's Shame Rational?}

Like many other survivors, Levi felt deep shame (or guilt) after his liberation. But what was he ashamed of? It was not at all a trivial endeavor for him to determine what the actual sources of his shame might have been. And, yet, a number of them were finally discerned. Firstly, there is the fact that he had systematically accepted being diminished and humiliated, without the slightest reaction on his side (Levi 1986: 56-7). Secondly, he accuses himself of failure in terms of human solidarity, that is, of omitting to offer help to those who were weak and helpless. This was actually perceived among prisoners in Auschwitz as a more serious failure than deliberately hurting or robbing someone (Levi 1986: 58-9). There is, thirdly, the grey zone, that is, the fact that the Nazi machinery could not have been so efficient and operative without the prisoners' cooperation, which constitutes what Levi famously named 'the grey zone' (Levi 1986: ch. 2). Even though his participation in the grey zone was not all significant, Levi was still haunted by memories of his little acts of cooperation and also with his inability to confront in any relevant way the Nazi machinery itself (Levi 1986: 28). Fourthly, Levi feels guilty (or ashamed) at the mere fact of 
having survived. For, in his view, the best (that is, those who didn't accept humiliations, were generous with the weak or rejected to cooperate with the Nazi machinery) were quite unlikely to survive. The vast majority died. Only the worst, the selfish, have survived and this makes Levi feel like a fraud: "I might be alive in the place of another, at the expense of another" (Levi 1986: 62). And, finally, there is the shame of the world: people may feel shame for the crimes that others, and not themselves, have committed. For, after his experience in Auschwitz, Levi could no longer close his eyes to the fact that "no man is an island" (Levi 1986: 65).

I must unfortunately leave aside a detailed exploration of Levi's nuanced account of his shame and focus on a very specific question, which often came back to him: 'Is my shame (and that of other survivors) rational?' At first sight, it may seem that it wasn't, at least if the notion of control is to play a relevant role. For, given the extreme conditions of survival in Auschwitz, one can hardly ascribe to Levi the room for maneuver, the amount of control over his actions and omissions, that is usually required to impute moral responsibility. There was, besides, no conspicuous action by which he had contributed to the Nazi machinery, or any sense in which he had significantly failed to offer help. This is why, at some point, he concludes that there is nothing on his side to be ashamed of from the viewpoint of rationality:

Therefore, on a rational plane, there should not have been much to be ashamed of, but shame persisted nevertheless, especially before the few, bright examples of those who had the strength and possibility to resist. (Levi 1986: 58. See 1986: 54)

Nevertheless, the question as to whether his shame was really justified remains for him unresolved:

Is this belated shame justified or not? I was not able to decide then and I am not able to decide even now, but shame was there and is there, concrete, heavy, perennial. (Levi 1986: 61)

There seems to be a tension between what rationality tells Levi to feel and what he actually feels. This may sound, though, like a very familiar situation: after all, people's feelings are quite irrational on many occasions. So, why shouldn't we regard Levi's shame as just an irrational response? I will certainly resist such a conclusion, even though the general grounds for my dismissal will only be elaborated in Chapters 5 and 6. We may, for now, focus on how Levi might react to such a conclusion. He could not defend his shame as rational, as we have seen; but he was also unable to discard it as purely irrational. This is, indeed, a rather unstable position badly in need of some explanation. And, for this purpose, we cannot confine ourselves to Levi's explicit claims on the issue, but must contemplate any other remarks 
and attitudes that may reveal the significance that his shame actually had for him. On the basis of this wider body of evidence, we may reasonably conclude that, even though Levi may not have felt entitled to judge his shame as either rational or irrational, he felt forced to be faithful to it. This is to be inferred both from the way he actually shaped his life after liberation and from some recurrent remarks about the 'strong and durable impulse' that induced him to keep writing on the Nazi machinery and his experience as a survivor:

I could not say whether we did so or do so because of a kind of moral obligation towards those who were silenced, or rather in order to free ourselves of their memory; certainly we do it because of a strong and durable impulse. (Levi 1986: 64)

Some people will certainly be inclined to interpret this impulse, this 'feeling forced to', as a merely neurotic disposition, given that Levi himself could not recognize it as rational or proportional to the facts. This is, however, a temptation Levi explicitly resists, as his own reluctance to discard it as simply irrational seems to confirm (Levi 1986: 64-5). The rationale behind this reluctance was, it seems to me, that obedience to such an impulse was not at all perceived by him as base or degrading, but, on the contrary, as part of a demand that he could not ignore without feeling debased:

It was not possible for us, nor did we want, to become islands; the just among us, neither more nor less numerous than in any other human group, felt remorse, shame and pain for the misdeeds that others and not they had committed, and in which they felt involved, because they sensed that what had happened around them in their presence, and in them, was irrevocable. (Levi 1986: 66)

We may, however, take advantage of Levi's uncertainty as to whether his shame was rational in order to argue for the existence of a mismatch between his actual c-judgment at time $T_{1}$ and a hypothetical c-judgment that he might have issued at time $\mathrm{T}_{-1}$, that is, a time previous to his deportation to Auschwitz. In this respect, he argues that, as a prisoner in Auschwitz, he did not have enough room for maneuver so that he might reasonably be held responsible for whatever actions he may actually have done or refrained from doing. He is, therefore, convinced that no one could reasonably object to the fact that he did not act otherwise, so that he might have resisted humiliations or fought in one or another way the Nazi machinery:

Changing moral codes is always costly: all heretics, apostates, and dissidents know this. We cannot judge our behaviour or that of others, driven at that time by the code of that time, on the basis of today's code; but the anger that pervades us when one of the 'others' feels entitled to 
consider us 'apostates' or, more precisely, reconverted, seems right to me. (Levi 1986: 61)

This line of reasoning rests, however, on two significant assumptions. One such assumption is commonly mentioned in philosophical debates and also in everyday discussions, namely:

The Control Constraint: a relevant degree of control or room for maneuver over one's actions is a necessary condition for the rationality of one's shame.

But the second assumption is rarely invoked:

The Third-Party Constraint: if no one can legitimately accuse me of having done something shameful, my shame is not rational.

It follows from these two assumptions that an experience that Levi regards as central to his life, namely, his shame as a survivor of Auschwitz, is to be dismissed as purely irrational. In view of this conflict, one may feel tempted to either revise the role that rationality must play in our lives or instead challenge the conception of rationality that such constraints presuppose. This is an issue I will return to in later chapters but, in any event, Levi's hesitation suggests that the Control and the Third Party Constraints (as well as the corresponding conception of rationality) are deeply entrenched in our culture. ${ }^{17}$ They are so deeply ingrained that he was unable to challenge them even though they were clearly in conflict with some central aspects of his own experience. Consequently, one should expect such constraints to have shaped Levi's hypothetical c-judgments at $T_{-1}$, that is, before his deportation to Auschwitz. Thus, we say that, had Levi been asked at that time whether shame at $T_{1}$ would have been rational, his hypothetical c-judgment would have fallen on the negative side, that is, he would have endorsed the claim 'In the standard case, the survivor's shame is irrational'. Thus, we seem to be confronted with a mismatch between a hypothetical and an actual c-judgment. A hint is, besides, provided as to why our hypothetical c-judgments may tend to depart from our actual c-judgments on occasions like this, namely, because our hypothetical c-judgments are shaped by some stereotypical assumptions people can hardly become aware of even after conscientious deliberation. One may regard the interference of such assumptions as a failure in deliberation, but barely of the kind relevant to our purposes insofar as there is reason to think that Levi (and, in general, any cultivated and reflective person) could not have surmounted it at $T_{-1}$, that is, from a merely hypothetical perspective. It must not be inferred from the existence of this kind of mismatch that our actual c-judgments should always prevail, though, since this may vary from one to another occasion. Yet, to make my case against the original position, I only need to show how 
it is that the actual c-judgment must be privileged on some relevant occasions. And this is what seems to happen in Levi's case insofar as his actual c-judgments on his experience as a survivor are regarded as classic, that is, as a continuous source of understanding with regard to what happened in the Nazi extermination camps and the kind of response it calls for.

Several objections stand in the way of this line of reasoning. Let me just consider two which seem fundamental, even though they point in opposite directions. Firstly, some may object that we cannot trust the victim's voice because the emotional immediacy of her experience is likely to distort her judgment. From this perspective, the victim's judgment about her own plight could not be acknowledged as considered, given that a certain distance seems indispensable for an impartial and authoritative judgment to be obtained. A trivial implication of this line of reasoning is that Levi's view could hardly challenge the Matching Assumption, since his actual judgment at $T_{1}$ does not qualify as considered insofar as it is inevitably tainted with his experience in Auschwitz. There is, however, a second objection that points in the opposite direction: instead of discrediting the victim's voice, some may be inclined to vindicate the capacity of hypothetical deliberation to bridge the gap and be as insightful as any actual deliberation could be. Thus, some may stress that Levi's case shows at most that people's hypothetical reflections on certain matters tend to be unsatisfactory, but this does not rule out that a more conscientious process of hypothetical deliberation might eventually bridge the gap and lead to a view as profound and insightful as Levi's at $T_{1}$ might have been. In other words, some may say that Levi's case may bring to light the fact that most people only come to understand the full significance of certain facts whenever they may actually face them, but this gives us no reason to conclude that a sufficiently detailed hypothetical deliberation could not have delivered similar results, so that there is no deliberative advantage of our actual c-judgment that could not have been appropriately counteracted by further hypothetical deliberation and, therefore, the Matching Assumption could finally be retained. It seems then that the first line of objection assumes that victims are in a rather inadequate position to judge their own case, whereas this second one grants the accuracy of their judgment and just denies that there were serious reasons to rule out that a similar judgment could be attained by mere hypothetical means. I will examine now why these two lines of objection not only conflict with each other, but are untenable on independent grounds. Let me take the second objection first.

\subsubsection{The Modality of 'Could'}

The second line of objection hinges on a fundamental claim:

(C1) One could always have reached Levi's actual c-judgment by a more conscientious hypothetical deliberation. 
Some constraints must be placed, though, on the modality of 'could' if claim (C1) must serve to vindicate the original position in front of Levi's actual c-judgment. For such a hypothetical position was presented as $a$ device of representation, and actual devices have some operating conditions that limit the modality of 'could'. But, what could those operating conditions be? It sounds reasonable to assume that such conditions must somehow refer to our human capabilities and the circumstances in which they are normally exercised. Moreover, insofar as political liberalism conceives of all agents as free and equal, it seems that the capacities at play in the original position must be quite common in adult human agents. We may thus restate claim (C1) as follows:

(C1*) Under normal conditions, human agents could have reached Levi's actual c-judgment conclusion by a more conscientious hypothetical deliberation.

The worry is that Levi, despite being a rather cultivated person, may have failed to meet this challenge. For there is serious reason to think that he could not have reached at time $T_{-1}$ the sort of considered judgment that as a survivor he felt the need to acknowledge. It has been argued, moreover, that his failure didn't hang on any idiosyncratic features of his, but instead on the way stereotypical assumptions may secretly bias anyone's hypothetical deliberation. In particular, Levi seems to have been blinded by the Control and the Third Party Constraints, whose deeper roots are still to be examined and will eventually stress the power of the mechanisms that stand in the way of a satisfactory hypothetical assessment of some crucial experiences of harm. The kind of awareness and deliberative practice that may serve to compensate, or at least attenuate, the impact of such mechanisms will be explored in the chapters to come, for it may thus improve our ability to appropriately respond to harm.

Some might try to avert the negative implications of $\left(\mathrm{C}^{*}\right)$ for the deliberative relevance of the original position by clinging to claim (C1) instead and, thereby, denying that the modality of 'could' should at all be constrained by some normality conditions. This maneuver could hardly be of any avail to defend the original position and, in general, the significance of hypothetical deliberation for our ability to shape our lives. For, on the basis of that unrestricted modality, almost every deliberative device we may think of will meet (C1), given that there will always be some circumstances where some idealized agents would produce the appropriate results. Hence, it is unclear why the original position should be privileged over other hypothetical devices. Moreover, no plausible advantage could be ascribed to a hypothetical or detached kind of deliberation in opposition to a more committed one, since the lack of constraints on the 'could' would also apply to the latter. And who would want to deny that there are some circumstances where an ideal agent might overcome the tangles and difficulties 
of emotional attachment and succeed in achieving a rather impartial and considered view?

Some.may finally opt for a counter-attack as the best line of defense and argue that all sorts of deliberations involve hypothesizing to a certain degree. Even actual judgments, insofar as they may be considered, must indulge in hypothetical deliberation and, consequently, they will object that the very idea of a neat divide between actual and hypothetical c-judgments hangs on a confusion. I certainly agree that deliberation always requires a certain degree of departure from the actual world and the contemplation of some counterfactual possibilities. My worry about the original position is not so much, however, that some hypothesizing is involved, but the particular way in which hypothesizing is conceived of within such a procedure. In general, Rawls seems to be convinced that, since every deliberation is to some degree hypothetical, the specific degree to which any given deliberation may depart from actuality is of no significance, whereby there is no reason why we could not dispense with actual c-judgments in our deliberation behind the veil of ignorance. This line of reasoning is to be favored, moreover, by the widespread conviction that an impartiality of judgment requires emotional detachment. Mere hypothetical deliberation is, as a result, enhanced not only because there appears to be no conceptual reason to privilege actual c-judgments, but also because the latter are at odds with the demands of impartiality so crucial to matters of social and political justice. Moreover, the design itself of the original position takes it for granted that the sort of impartiality required to determine the principle of political justice excludes that any particular agent might have a privileged deliberative position on such matters. And this provides an additional reason why, even on issues concerning reparation, Levi's actual c-judgments are to be dispensed with to the benefit of our hypothetical c-judgments.

I am certainly willing to stress the relevance of impartiality for any deliberation concerning social and political justice and, in general, moral issues. Even so, I will argue that any reasonable notion of impartiality must take into consideration the privileged role that an agent's actual c-judgment may eventually have in moral deliberation and, more specifically, whenever matters of political justice and reparation are concerned. To some, this suggestion may sound on the verge of contradiction. For, on the standard conception of impartiality, there is no conceptual room for such privileges. Yet, such a response may beg the question against my proposal. For it seems that, according to reflective equilibrium, we must first scrutinize some cases where impartiality (or the lack of it) may easily be recognized, and then raise the question as to how much uniformity in the role of the different agents is actually required in such contexts. This is, indeed, a tricky exercise. For, given how easily our theoretical pre-conceptions permeate our perceptions, those in the grip of the Kantian approach will tend to see in the experiences I may appeal to just an exemplification of the notion of impartiality I am trying to challenge, and deny, as a result, that any evidence was being 
supplied to support my view. In fact, this is what one should expect if, as I defend, the notions of rationality and impartiality that are presupposed in the original position (and in the Kantian approach, in general) are so deeply entrenched in our lives (and, in this sense, constitute a cultural stereotype) that moral situations are already experienced in the light of those notions. My point is, however, that such a conception not only offers a distorted view of our moral experiences, but severely hinders our capacity to articulate a more appropriate response to harm. My hope is that, as Levi's shame and some other experiences of harm will be examined (Chapters 2 to 3), those who may initially oppose my suggestion will first accept the overall idea that there may be a gap between an agent's actual experience of harm and how she may initially have identified it and, secondly, recognize some of the mechanisms in virtue of which the Kantian approach distorts our experience of harm to the detriment of our capacity to respond to it more appropriately (Chapters 4 to 6). On this basis, I will elaborate in sections 5.2-5.3 a notion of impartiality that is meant to make room for the fact that an agent's actual c-judgments may prevail in some circumstances.

\subsubsection{Specific Reason and the Fears of Detachment}

There is still the first objection to the epistemic relevance of Levi's actual c-judgment to be examined. The fundamental concern was that victims are typically so attached to their respective experiences that one cannot reasonably expect their voice to be accurate and faithful to the facts. Due respect must undoubtedly be paid to Levi's account of his experience as a survivor, but quite a different matter, some may argue, is whether his verdicts should really be trusted, since his emotional attachments may easily have led him astray. This line of objection relies, however, on a certain stereotype that may not ultimately be attested by evidence: it jumps from the trivial fact that our emotional attachments tend to cloud our minds to the conclusion that they necessarily interfere with our deliberative capacities and to such a degree that the victim's voice must be dispossessed of any authority as to the nature of her own plight. And, yet, I will argue that not only emotional attachments but also emotional distance may seriously bias (and, in general, diminish) our deliberative capacities. It follows that if we had to dismiss the victim's voice just for the risk of distortion, we should refuse the voice of the detached agent as well. Hence, if any voice is to be trusted, we must renounce the idea that a testimony is not at all credible simply because there is a general risk of distortion, and instead examine each particular case to see whether there is specific reason to dispense with one or another report. Let me now briefly suggest why emotional distance may bias our deliberation, although a more detailed discussion of this issue will be saved for Chapters 2 and 3.

To begin with, we may focus on the fact that, as Elaine Scarry puts it, "every weapon has two ends" (Scarry 1987: 59). Some deep metaphysical 
and epistemic asymmetries emerge, though, between those who occupy the respective ends. Those who hold the weapon have, metaphysically speaking, the power to hurt and, epistemically, the capacity to look away from the pain being produced and even doubt the intensity of it. By contrast, those who face the cutting edge are, from a metaphysical point of view, transformed into people who can just be hurt and who certainly can't deny the pain to which they are being subjected. As I will argue in Chapters 2 and 3, these metaphysical and epistemic asymmetries induce third agents to perceive the torturer's action as justified and the victim's demand as illegitimate. Such appears to be the essential role of interrogation, whose question is stereotypically construed as providing a motivation (and, tacitly, a justification) for the pain being inflicted, and whose answer is almost inevitably viewed as a betrayal. All this in the absence of any specific evidence to justify this particular interpretation of both the question and the answer. It is clear, however, that by this elementary procedure, the initial sympathy for the victim's pain and the moral perplexity over the torturer's action are reverted and transformed into a justification for the infliction of pain. But why is it that, despite our initial sensitivity toward the victim's plight, the interrogation can so easily subvert our moral attitude toward her? This is a question to be explored mainly in Chapters 2 and 3, where some psychological mechanisms will be highlighted to account for this tendency to neglect the victim's predicament and support the torturer's action. Such mechanisms have to do with a variety of fears. The most trivial of which is this: if third agents regarded the torturer's action as arbitrary, they would perceive themselves at risk insofar as the torturer's weapon would then appear as only accidentally away from them; but if the contrary were true and the infliction of pain on the victim's body were a legitimate maneuver of self-defense, then third agents would feel protected by the same agent who looked so dangerous from the previous perspective. ${ }^{18}$ All this suggests that emotions may not only cloud the victim's mind, but bias the views of third agents and their hypothetical judgments, even if they are the result of conscientious deliberation. Yet, once all parties are at risk of distortion in the benefit of their respective psychological needs and dispositions, it seems that specific reason must be mentioned if one or another voice is to be either trusted or discredited. ${ }^{19}$ Let us now see why Levi may be so reluctant to regard his shame as rational, and also why a proper answer to this question may call into doubt the Matching Assumption.

\subsubsection{Who Can Judge the Sondernkommandos?}

The idea expressed by the Third-Party Constraint, namely, that the limits of morality coincide with those of a third-person accusation, may lie at the core of Levi's reluctance to acknowledge the rationality of his shame. For he was adamant in rejecting the idea that a third party might be entitled to accuse him (or any other survivor) of having done something shameful. In 
this respect, he emphasizes the legitimacy of his anger (and that of other survivors) at those who may feel authorized to judge him despite their lack of acquaintance with any experience that might remotely resemble Auschwitz:

We cannot judge our behaviour or that of others, driven at that time by the code of that time, on the basis of today's code; but the anger that pervades us when one of the 'others' feels entitled to consider us 'apostates' or, precisely reconverted, seems right to me. (Levi 1986: 61. See 1986: 58)

It is true that, as Levi himself emphasizes, extermination camps could only have been so efficient due to the prisoners' massive cooperation in their activities. And, yet, he insists that no human court, no third party, has the authority to judge their actions:

The condition of the offended does not exclude culpability, and this is often objectively serious, but I know of no human tribunal to which one could delegate the judgment. (Levi 1986: 29)

A moral evaluation about what survivors might have done in the extermination camps should, in any case, "be entrusted only to those who found themselves in similar circumstances, and had the possibility to test on themselves what it means to act in a state of coercion" (Levi 1986: 28-9). He feels, thus, entitled to draw some distinctions as to the judgment that different survivors may deserve given their respective contributions to the Nazi machinery. He does not hesitate, for instance, to condemn the Kapos (i.e., foremen of a prisoners' party), but reserves his judgment as to the members of the Sondernkommandos, namely, those prisoners who led newcomers to the gas chamber, including their own neighbors or even members of their own families. Despite the disgust that their actions may arouse, Levi decides to withdraw judgment. He is convinced that no one (not even other survivors) is actually in a position to judge them. Thus, Levi seems to grant that there are some cases where an agent may have performed a morally horrendous action and still no third party is entitled to judge her, not even those who may actually have confronted a relatively similar situation. And, yet, it may make sense for the agent herself to feel ashamed or guilty as a result of what she did or refrained from doing.

We may, in view of this, renounce the Third-Party Constraint and accept that the limits of morality do not overlap with those of third-person accusation. For there are cases, precisely those where the Control Constraint is not met, in which an agent may legitimately accuse herself of having done something shameful but, nevertheless, no third agent is entitled to accuse her of such a thing. To put it another way, we may say that Levi was trapped in the following line of reasoning: (a) he took for granted both 
the Control Constraint and the Third-Party Constraint, but (b) strongly rejected the idea that a third-party could legitimately accuse him, whereby he concluded (c) that his shame was not rational. He was, though, also reluctant to dismiss it as a purely irrational and idiosyncratic reaction. A reasonable way to make sense of this reluctance is to challenge the ThirdParty Constraint, for that way we make room for Levi's shame to be rational despite the fact that no third party is entitled to judge him given that he did not possess the required degree of control. A trivial consequence of this is that the Control Constraint must be dropped too, given that the conditions under which an agent may legitimately feel responsible for her actions (and omissions) do not reduce to those cases where the agent is relevantly in control.

So, it seems that the privileged epistemic authority of those who, like Levi, have faced some harsh experiences of harm derives not only from the fact that, given our psychological condition, human beings are unable to grasp some aspects of a moral situation unless they actually face it, but also from the fact that, in some situations where the Control Constraint is not met, agents may still experience an accusation that appears to them as both inescapable and strictly first-personal. It is first-personal because only the agent herself is entitled to make such an accusation, and it is inescapable insofar as some sort of necessity is involved. It is hard to see, however, how one could make sense of this kind of necessity within the Kantian approach. For it is not rational necessity as it is conceived of within that approach because it is agent-relative and, therefore, cannot be established from a detached, impartial perspective. But neither can it be construed as the kind of necessity that the Kantian approach ascribes to passions. For Levi's experiences involve the question, clearly unintelligible with regard to blind passions, as to what being faithful to his impulse may consist of and to what extent one may have succeeded in that respect. The need to elucidate this kind of necessity will come up at different stages in this essay, but only in sections $6.5-6.9$ will it be examined more systematically.

In view of all this, some may feel inclined to accept the aforementioned asymmetry between the first-person and the third-person perspectives, as well as its implications both for the relevance of hypothetical c-judgments and the notion of impartiality; and, yet, resist the conclusion that the original position should be rejected as an efficient device to determine the fundamental principles of justice for the basic structure of a society, since they may question the relevance of Levi's experience for issues of social and political justice. Still, the notion of reparation may be of some use in this respect. For how Levi's shame is ultimately construed (namely, as a rational response or, instead, as sequel of a traumatic experience) seems crucial to determine the kind of reparation that a society owes to the victims of massacres and genocides, as well as to the role that the victims' voices may have in that process; and I do not think anyone doubts that these issues must play a significant role in a theory of political justice. 
To stress an aspect in which Levi's experience may be of relevance to that theory, let me recall that the original position assumes that the principles of justice are to be agreed upon by individuals who would otherwise be unbound to them. This suggests that agents, as they are conceived of in the original position, are only contractually linked to the principles of justice for the basic structure of a society. But if social and political justice is central to our life in a society and the principles that must govern our social life are to be determined by means of a contract, how are we to conceive of the fundamental bond that brings individuals together within a certain society? Should it be regarded as merely contractual as well? It is true that Rawls insists on "the profoundly social nature of human relationships" (Rawls 2005: 259). The question is how that 'profoundly social nature', and the constraints upon its depth that derive from the role ascribed to the original position in his conception of political justice, are to be construed. In this respect, Levi's experience of shame seems to reveal the existence of a deep bond among human beings: we are not islands; that is, people may legitimately feel guilt or shame for things that others, and not themselves, have done. At first sight, this bond is quite foreign to the idea of a contract. For it does not appeal to either the idea of a decision that an agent may make or to the conclusion of a deductive argument. The demands that the drowned (the name by which Levi refers to those who were murdered in Auschwitz) impose upon Levi are not so much a matter of decision, but of acknowledgment or recognition (sec. 6.5). They are demands that no third party is entitled to make upon him, and still he feels forced to recognize them as essential to his humanity. These asymmetries between the firstperson and the third-person perspectives imply that failure to be faithful to such demands could hardly be paralleled with the infringement of a contract. Some may reply, however, that failure to honor some contracts often comes with an experience of degradation, and this suggests that a deep bond may already be present in the idea itself of a contract. But, in such a case, we ought to spell out how much of our humanity is involved in the acceptance of a contract and how the elements at play are to be accounted for with the limited resources comprised in the original position. So, the dilemma seems to be: either we stick to the original position as it was initially designed, but then it is hard to understand the kind of bond that Levi's experience suggests and the demands concerning reparation that it imposes; or instead we decide to enrich the resources to which one may appeal to in the original position, but then it is hard to understand how our deliberation in that position could still be purely hypothetical and independent of the agent's specific commitments and character. So, we may conclude that a deliberation behind the veil of ignorance is not necessarily advantageous with regard to issues of political justice and reparation. For that sort of deliberation may be misleading not only because the agent's judgment might inadvertently be distorted by some stereotypes and fears, but also because, as I have just pointed out, the fact that we are not islands 


\section{Morality, Self Knowledge and Human Suffering}

involves a kind of social bond that goes beyond the idea of a social contract and this, in turn, implies that some judgments concerning social and political justice are both inescapable and strictly first-personal.

\subsubsection{To Sum Up: Three Theses and a Few Strands}

The original position has been presented as a device that delivers by mere deductive means the principles of justice for the basic structure of a society, as well as the particular judgments concerning justice that each particular occasion may deserve. Even if this device operates deductively, the fact that it may pass the reflective equilibrium test cannot be determined by such means. The ability to meet this constraint depends instead on whether this particular procedure may really track our considered judgments on issues of social and political justice, and it is essential to this purpose that such judgments are individuated by means that are reasonably independent of the fact that they can be deduced from the original position. For, otherwise, we would be trivially begging the question. Reason has been provided to doubt, however, that the original position might meet this demand insofar as our hypothetical c-judgments and our actual c-judgments may not match even in the absence of any relevant mistake, that is, any mistake that an agent could reasonably be expected to overcome from her own stance, either hypothetical or otherwise. We may thus conclude as follows:

(T1) There is room for relevantly flawless mismatches between our hypothetical c-judgments and our actual c-judgments and, derivatively, between the latter and our original c-judgments.

In the previous sections, I have challenged a rather general strategy to preserve the Matching Assumption (and, consequently, deny (T1)) in virtue of the alleged fact that, in cases of mismatch due to a flaw in the agent's hypothetical deliberation, the agent could always have reached the appropriate conclusion by perfecting her capacity to deliberate hypothetically. In particular, I stressed that 'could' there allows for two main interpretations, neither of which favors a defense of the original position as a suitable device of representation. On the first interpretation, the original position is regarded as an actual device and, consequently, the modality of 'could' is to be constrained by some operating or normality conditions. But, in this case, it is false that agents could always (or even often) have reached the adequate conclusion, as Levi's experience (as that of many other survivors) may suggest. On the second interpretation, the modality of 'could' will not be subject to any normality constraint. From this perspective, the original position will certainly appear as an infallible, but could hardly be privileged over other devices that may equally become infallible insofar as no normality constraint is imposed. ${ }^{20}$ 
The second objection bears on a more empirical consideration to be further developed in the chapters to come, namely, the role that our cultural stereotypes may play in hypothetical deliberation. Thus, I have first stressed how such stereotypes may unknowingly affect an agent's hypothetical deliberation and, as a result, hinder her capacity to make sense of her own experience. Secondly, I have suggested that some stereotypes permeate our conception of impartiality, such that they are associated with some fears that third agents may exorcise by discrediting the victim's voice and endorsing the torturer's legitimizing discourse (sec. 2.2, 3.4, 5.4-5.6). In the light of this, we may conclude that, even if there may be some general reason to doubt the accuracy of the victim's voice, there are also some serious reasons to mistrust the judgment of a detached, third party (sec. 2.6, 2.8 ); and this may suffice to defend (T3):

(T3) Cultural stereotypes may severely distort our hypothetical c-judgments.

It follows that a detached, third party is not necessarily in a better deliberative position than those who are emotionally involved in the situation at stake. One should then get into the details and nuances of every particular situation in order to discern on every occasion whose voice is to be trusted and in which specific respects. And this may sufficiently support (T2) (and, derivatively, (T1)):

(T2) In some relevant cases of flawless mismatch, our actual c-judgments must prevail.

Let me, finally, suggest that (T1)-(T3) may apply not only to the original position, but also to many other thought experiments in the current ethical and meta-ethical debates. For, insofar as thought experiments involve a highly hypothetical kind of deliberation, they may mislead us by secretly projecting upon the imaginary situations at stake some deeply entrenched cultural stereotypes, like the Third-Party and the Control Constraints. It is, however, a matter of further elucidation to determine the extent to which any particular thought experiment may be affected by this bias and, derivatively, the specific way in which (T1)-(T3) may apply to each of them. This task certainly goes beyond the scope of this essay, whose main purpose is not methodological, but is to elucidate the conditions under which a more appropriate response to harm may be favored. And, in this respect, a few substantive claims have already been made. Firstly, I have stressed the existence of some mechanisms of distortion that may be present in our attempt to assess the moral significance of some hypothetical situations. A more detailed account of some such mechanisms and their deep significance in our lives will be developed in Chapters 2 and 3, as well in sections 5.4-5.6. Secondly, the depth of such mechanisms suggests that the idea of a 
single impartial point of view from which moral situations are to be ideally assessed may not make sense ultimately. In fact I will argue that, contrary to what Rawls' original position assumes, the agent's character must play a crucial role in our ability to ponder on the moral significance of any given situation. This is connected to the third point I would like to highlight, namely, that in moral deliberation a certain kind of necessity is involved, which is neither blind like passions nor impersonal as rationality is often claimed to be. This sort of necessity is essential, as we have seen, to Levi's deliberation and his need to challenge the Third-Party Constraint. Thus, we reach the fourth point, namely, the deliberative (and moral) significance of the asymmetries between the first- and third-person perspectives to the effect that, even though someone like Levi may legitimately regard his shame as rational and proportional to the facts, no one else is entitled to accuse him of having done anything shameful. Some significant implications of these four points for the way we should respond to harm, as well as for our ability to lead a meaningful life, will be explored in the chapters to come. Before that, let me briefly characterize in a more systematic way what I regard as the hallmarks of the Kantian approach.

\subsection{THE KANTIAN APPROACH}

The Kantian approach to morality ought not to be confused with what may eventually be presented as Kant's view on such matters. A certain reading of Groundwork of the Metaphysics of Morals (Kant 1977) lies, however, behind most of the claims and distinctions I attribute to the Kantian approach. Focus on this book would certainly be quite problematic were I trying to identify Kant's view as such, since it has recently been argued, for instance, that a more sophisticated and plausible account of morality is to be found in some later books of his, like The Metaphysics of Morals (Kant 1996) and Religion within the Boundaries of Mere Reason (Kant 1998) (Korsgaard 2009: 153-8; 2002: 19). A detailed study of Kant's view is, in any case, beside the point of this essay, whose main concern is not so much to discuss one or another specific view about morality, but to challenge a kind of approach that permeates our moral experience and that a number of philosophical views have tried to articulate. Of course, such an approach must bear a relevant relation to Kant's writings in order to qualify as Kantian at all. And it may suffice, in this respect, to trace back to Kant's most influential works on morality the network of distinctions and claims that, in my view, compose the Kantian approach. In the hope that this constraint will reasonably be met, I will now turn to Rawls' original position and Levi's experience of shame in order to revisit the distinctions and claims that have been introduced in the previous discussion, and in light of which I will later enumerate what I take it to be the hallmarks of the Kantian approach. 
The original position is meant to provide a representational device to determine the principles of justice for the basic structure of society. All this is based on the assumption that one is confronted with a stable society "divided by reasonable though incompatible religious, political, and moral doctrines" (Rawls 2005: xviii). A starting point for this inquiry is certainly the question as to how citizens of disparate persuasions may at all attain $a$ reasonable agreement. Rawls seems to be convinced that this can only be done by drawing a neat distinction between the kinds of reasons that may derive from anyone's comprehensive doctrine and those that, leaving aside any specific conception of the good, may feature as a public basis of justification (Rawls 2005: xix). Such a public basis seems to require a certain contrast between form and content, inasmuch as the range of comprehensive doctrines to be taken into account is exclusively constrained by their reasonableness, and therefore no substantive claim may constitute a common ground on the basis of which a relevant agreement could be reached, except those (if any) substantive assumptions that might eventually be involved in the idea of reasonableness itself. In other words, any procedure to determine the principles of justice that may serve the purposes of political liberalism must reduce substantive assumptions to a minimum. ${ }^{21}$ It is not so much that one ought to dispense completely with them, but only that one must try to rely almost exclusively on those features that are constitutive of the liberal project, namely, the idea of a stable and just society of free and equal citizens with a plurality of reasonable comprehensive doctrines. ${ }^{22}$ Here it is where the original position seems to enter into the picture.

As such, the original position does not explicitly appeal to the notion of reasonableness that is indispensable to identify the kind of agreement that political liberalism is looking for. Yet, as Rawls himself stresses, such a notion is present in the design itself of the thought experiment, where certain conditions are established to ensure that the agreement that might eventually be reached should count as reasonable (Rawls 2005: 25, 72-3). Such conditions reduce ultimately to one: deliberation in the original position must take place behind the veil of ignorance. This constraint presupposes again a certain distinction between form and content, since the veil of ignorance is conceived of as thick rather than thin, for it is assumed to leave aside our knowledge of the reasonable comprehensive doctrines that may actually be present in a certain society (Rawls 2005: 24-5). All this is not to conclude that substantive considerations can be entirely absent behind the veil of ignorance, but rather that they should be kept at a minimum if the goal of political liberalism is to be achieved (Rawls 2002: 141).

Deliverances of the original position must in any case be checked, as we have seen, against our considered judgments and convictions at all lévels of generality (Rawls 2005: 8). To put it another way, those principles that everyone in the original position might agree upon must match the content of another sort of agreement, which can no longer be merely hypothetical, but actual or historical, namely, those considered judgments and 
convictions we may actually agree upon, once "they have been duly pruned and adjusted" (Rawls 1999: 18). They constitute the bedrock against which the products of the original position must be tested. This sort of match is constitutive of the process of reflective equilibrium that Rawls regards as the touchstone of any conception of political justice. For he rules out that there might be some independent facts that any such agreement should track. This involves a rejection of a realist approach to political justice and a consequent exclusion of moral perception in the elucidation of the principles of justice (Rawls 2005: 113; 2005: 91-2). As a result, Rawls concludes that principles of justice are not there to be discovered, but must be constructed instead (Rawls 2005: $\mathrm{xx}-\mathrm{xxi}$ ). This anti-realist view of political justice may certainly be encouraged by the plurality of reasonable comprehensive doctrines that are claimed to coexist in a liberal society, but it can also be grounded on the conception of the world allegedly favored by the development of the natural sciences. For it seems that, according those sciences, the world as it is, independently of our purposes and interests, is dispossessed of any axiological property and, therefore, it is hard to see how there could be any grounds for our evaluative judgments (including those concerning justice) beyond what people may reasonably agree upon. This line of reasoning takes for granted a certain metaphysical view, namely, the naturalistic, disenchanted conception of the world (Kant 1977: 4:446-63; 2002: 3-13, 161-3). Yet, according to Rawls, political liberalism should remain as metaphysically uncommitted as possible. In fact, he suggests that political liberalism is consistent with moral realism ('rational intuitionism' as he calls it) and, therefore, with a denial of the disenchanted conception of the world (Rawls 2005: 95). Yet, in the absence of a commitment to such a conception, his constructivist approach will become essentially unstable, insofar as the existence of some independent evaluative truths would certainly impose some constraints on the sorts of agreements that may be regarded as reasonable. In fact, the Kantian approach tends to assume the disenchanted conception of the world, even though it acknowledges that people can't help but endorse one or another comprehensive doctrine insofar as this may be essential to their capacity to make sense of their own lives. Such an endorsement will undoubtedly involve some sort of selfdeception inasmuch as any such doctrine is likely to comprise some metaphysical commitments that, from a naturalistic (and allegedly impartial) perspective, are to be discarded as illegitimate. Some may thus argue that it is on the basis of such illegitimate commitments that people may misleadingly regard themselves as perceiving one or another moral aspect of any given situation. Thus, we have not only an argument against moral realism, but also an account of why people tend to mistakenly ascribe moral features to the world. Yet, Rawls cannot coherently rely on a naturalistic view to ground his constructivist approach, since, otherwise, he would depart from the sort of metaphysical neutrality that the project of political liberalism allegedly requires. But I do not see how he could coherently give up 
that metaphysical commitment either. For, in such a case, it is unclear how a merely constructivist approach may suffice to ground the principles of political justice, given that the existence of some independent moral facts that they might fail to track could not then be metaphysically excluded.

Moreover, a certain conception of the self and its deliberative capacities is essential to the original position and, in general, to the Kantian approach itself. Rawls is obviously eager to deny that his thought experiment should involve a commitment to one or another metaphysical conception of the self, since, otherwise, the original position may privilege one comprehensive doctrine over another to the detriment of the kind of impartiality that political liberalism appears to aim at (Rawls 2001a: 19; 2005: 27-35). Even though a complete metaphysical picture may not be presupposed, some assumptions about the self and its deliberative capacities are arguably present in the design itself of the original position. The worry is that these assumptions may not be as neutral and uncontroversial as political liberalism may demand; to identify them, we may appeal to a standard representation of the idea of justice, namely, the image of a balance scale. This image is so deeply entrenched within our culture that it serves to illustrate a number of closely interconnected aspects of our world-view, some of which will help us to articulate the hallmarks of the Kantian approach at the end of this section.

Take a balance composed of a beam, two pans, and a pointer. The search for justice is represented by an agent's ability to take into consideration the relevant circumstances of the parties in dispute. Every aspect of such circumstances may thus count as a weight to be placed on one or the other arms of the beam; once such a procedure has been duly carried out, the pointer will signal the course of action to be regarded as just. The balance is recognized as an image of justice inasmuch as it depicts the way in which an agent must deliberate about such issues. Rawls' conception of political liberalism certainly imposes some constraints on the kind of considerations that can have a weight in the process of determining the principles of justice that must govern the basic structure of a society: In short, they must appeal to reasons that are not dependent on any particular comprehensive doctrine, since the agreement to be reached is to be granted by people of disparate (although still reasonable) persuasions. The image of a balance thus serves to express this need for impartiality, which the veil of ignorance models in the original position. It is clear, however, that the scope of this image goes far beyond a theory of political justice, and appears to inspire the way we conceive of proper deliberation.

Such a view of deliberation has at least two complementary sources, which go hand in hand with the two previous lines of argument against moral realism, namely, (a) the need of a balance between competing (but reasonable) views or interests, and (b) the emphasis on the idea of a pure, detached observer, as the only one who may apprehend the world as it is, independently of us (Nagel 1986; Putnam 1992: ch. 5; Stroud 2000: ch. 2; 
Williams 1979: ch. $2 ; 1985$ : ch. $8 ; 2000 ; 2002$ : ch. 10). The overall idea comes to this: in order to deliberate in a truthful and impartial manner, the agent must depart as much as possible from her own character and, consequently, abstract away from any of its specific traits. Such a proposal hinges on two closely related assumptions: firstly, unless such a detached attitude is appropriately achieved, the agent's judgment (either theoretical or practical) will be blurred by her interests and prejudices and, secondly, traits of character are merely idiosyncratic and, therefore, dispossessed of any intrinsic normative value. Moreover, once an agent's character is dismissed as essentially distorting from the viewpoint of deliberation, it is hard to see how this picture of our deliberative capabilities might set any boundaries as to the moral issues a third party might be entitled to judge, and the ThirdParty Constraint is thereby vindicated.

This quite negative view of the role of character shows, indeed, in the way the identification of a public basis of justification is modeled by the original position. For agents are asked to deliberate leaving aside any antecedent knowledge about their own character and look for those principles of justice that people in the same deliberative condition would be ready to grant. The perplexity arises as to how it is that, just by pretending that one does not know one's own character, the distorting effect of the latter will be canceled out. In fact, it sounds rather inconsistent to claim, on the one hand, that an agent's character is not only deliberatively irrelevant, but tends to induce biased judgment and, on the other hand, that its distorting effects can easily be exorcised by a mere act of the will. For, wasn't it at least part of the worry that the strength of an agent's interests may inadvertently bias her decisions (Kant 1977: 4:405, 408)? How could one then expect a mere act of the will to be of any use to avert that kind of contamination? And here is where a second, extended use of the image of a balance comes in, namely, to depict our motivational framework.

There is, indeed, a certain understanding of our motivational framework that applies to our psychological condition the disenchanted conception of the external world. ${ }^{23}$ From this perspective, an agent's desires, inclinations, and interests act as weights to be placed on one or the other pans in the balance, so that the pointer will signal the resultant of those particular forces and, in the end, the kind of action the agent is most motivated to perform. Yet, this picture is badly in need of some alternative motivational resources if the idea of agency is to be preserved. The concern is that there seems to be no room for such alternative resources within a merely mechanistic picture of our motivational framework. To allow for them, we must shift to a deliberative understanding of the balance scale. On this understanding, the pointer shows the conclusion of an agent's deliberation, but provides no inkling as to the sort of motivational force the agent may appeal to in order to perform the corresponding action. If by chance the agent's conclusion coincides with the direction of the mechanistic pointer, there will be no motivational lack. But, in view of the previous considerations, this 
would just be a coincidence, given that the original position derives from the conviction that our desires and interests will easily lead us astray in matters of political justice and, consequently, that one should assume the existence of a systematic mismatch between the principles of justice one could reasonably agree upon and whatever actions our specific interests and desires may promote. So, it seems essential for this model to postulate the existence of some sort of motivational force that is alien to the agent's specific character and has, nevertheless, the power to eventually surmount her desires and interests to the contrary. There is, however, a significant amount of obscurity as to the intelligibility of a non-mechanistic force such that, firstly, interacts with the agents' mechanistic motivational framework and, secondly, there is a relevant sense of 'could' in which such a force, even if eventually defeated by the agent's inclinations, could always have prevailed (sec. 5.2, 6.7). 'The will' is, in any case, the name that the Kantian tradition has reserved for this kind of motivational force. ${ }^{24}$

A divided conception of the self seems to emerge as a result. A part of the self is composed by a set of mechanistic forces, which are not only dispossessed of any normative import (and are, in this sense, merely idiosyncratic), but tend to have a distorting impact on our deliberative abilities. Despite the power and energy ascribed to this portion of the self, it is usually regarded as passive, whereas the active side is reserved for the ability to deliberate and make decisions to which the self may manage to stick thanks to the effort of will, and despite any contrary inclinations. The Control Constraint (or even a more stringent variant of it) fits quite nicely with this conception of the self. For the active side of the self is assumed both to be fully under the agent's control and to embrace what is of real significance in her life. Hence, in matters of importance (and moral matters are certainly of that kind) no room is apparently left for luck and the Control Constraint is thereby vindicated. Yet, both the Control Constraint and the Third-Party Constraint will be under pressure if the divided conception of self is dismissed and the central role of luck in one's life is acknowledged. For, in such circumstances, one may begin to suspect that a third-party judgment must be confined to what an agent may reasonably be in a position to control, which in turn will no longer overlap with what is of most significance to her life. ${ }^{25}$

So far, I have sketched a number of assumptions and commitments that lie behind the original position and the role that Rawls ascribes to it within his conception of political justice. I will now take advantage of the previous considerations to characterize the hallmarks of the Kantian approach to morality as follows: ${ }^{26}$

1. The correctness of our moral judgments does not depend on their ability to track some facts that are in the world as it is in itself, independently of us, but on our capacity to reach an agreement of a certain kind. A realist stance about moral features is thereby excluded, and a constructivist approach endorsed. ${ }^{27}$ 
2. A crucial matter is then to identify the kind of agreement on which our moral judgments must be grounded. For this purpose, it is neither necessary nor sufficient that a certain agreement is actually reached among some particular people: some other constraints must instead be met. In this respect, a certain distinction between form and content seems imperative, given the plurality of reasonable world-views that people may actually endorse, together with the fact that moral realism has been denied. (Kant 1977, 4: 210-12, 388-89, 410-2, 420-1, 424, 434; Scanlon 1998: 5)

3. A procedure must, then, be formulated in such a way that it impartial with regard to the plurality of world-views and dispenses with the attribution of moral features to the world. Such a procedure must eventually deliver a system of principles in virtue of which moral issues are to be settled.

4. Moreover, impartiality with regard to the plurality of world-views seems to require the agent to abstract away from her specific character. This involves at least two assumptions: (a) unless such a detached attitude is appropriately taken, the agent's judgment (either theoretical or practical) will be biased by her interests and prejudices, and (b) traits of character are as such dispossessed of any deliberative value or, in other words, are merely idiosyncratic (Kant 1977: 4:410-1, 405, 407). No room is then left for a sort of first-personal deliberation that might go beyond the scope of a third-person perspective and, consequently, the Third-Party Constraint is established.

5. An agent's desires, interests and needs thus appear as distorting in virtue of their motivational force and, consequently, they must be counteracted by a different sort of motivation for the self to deliberate appropriately and be able to carry out the corresponding decisions and commitments. This non-mechanistic motivational force is commonly referred to as the will.

6. Thus, the Kantian approach seems to be committed to a divided conception of the self (Kant 1977: 4:413, 460-1). There is the passive portion of the self, which is composed of a system of motivational forces or inclinations that trivially motivate the agent to act in certain ways. Such forces are, nevertheless, blind and misleading: they are blind inasmuch as they are not assumed to track any properties in the world, ${ }^{28}$ whereas they are misleading because they tend to blur the agents' judgment to the benefit of their own purposes. On the active side is, hence, where agency truly resides. It consists of the agent's ability to deliberate leaving aside her passive elements, make decisions in the light of such deliberations and, finally, act correspondingly thanks to the effort of 
will that may eventually surmount any contrary passions or inclinations. The agent must then be held responsible for those actions and attitudes that her active side could reasonably control, which is the idea lying behind The Control Constraint.

7. Finally, the divided conception of the self assumes that the ultimate source of value lies in the active side of it. Yet, this side of the self has been conceived of as embodying the sort of impartial attitude that the Kantian approach regards as essential to morality, whereby the supreme importance of the latter is confirmed. It follows that moral principles must overrule any contrary demands that may spring from the passive side of the self and this is what the moralist view defends.

The purpose of these remarks is not, however, to enumerate a set of claims and distinctions that a particular view must endorse for it to be identified as Kantian. For those views that nowadays present themselves as such tend to revise one or another aspect of remarks (1) to (7). This happens in more than one way with Rawls' conception of political justice, ${ }^{29}$ and also with Christine Korsgaard's attempt to motivate a positive answer to the question 'Why should I be moral?' that I will examine in Chapters 4 and $5 .{ }^{30}$ It seems clear, though, that these accounts have actually been articulated as a revision and a partial vindication of the distinctions, claims and commitments assembled in remarks (1) to (7), ${ }^{31}$ which are thereby confirmed as hallmarks of a Kantian view. Consequently, we may recognize an account of morality (or a subdomain of it) as Kantian insofar as it is mainly inspired by remarks (1) to (7), even though one or another aspect of them may eventually be denied or qualified. There will be a number of borderline cases, but again it seems to me that they will be determined as such in virtue of how much they may depart from the constraints specified in remarks (1) to (7). Moreover, these remarks will contribute to the examination of the various ways in which some Kantian assumptions or commitments may be interfering with our capacity to adequately understand a certain moral situation. Some such interferences have already been highlighted with regard to Levi's shame, but will be further elaborated in later chapters with regard to some other experiences of harm.

Let me now turn back to the image of a balance. For I would like to suggest that, even though it has been commonly construed in the ways suggested above, it can also be employed to sketch an alternative model for morality (and self-knowledge), namely, the attentional model, which this essay is meant to elaborate. For this purpose, let us go back to the motto of this essay:

Action is the pointer of the balance. We must not touch the pointer but the weights. Exactly the same rule applies to opinions. If we fail to observe it there is either confusion or suffering. (Weil 1963: 44) 
As in the Kantian picture, the weights in the balance represent the agent's motivations. Yet, Weil's text suggests that, if an agent wished to modify the course of her action by the effort of will, she would be in a position similar to that of someone who wished to change the direction of the pointer by holding it firmly with her fingers. Inexorably, she would soon get tired and let the pointer go, which, after a few oscillations, would go back to the initial position, so that no reliable change in the agent's action will finally occur. In other words, and contrary to the Kantian approach, Weil regards the will as subject to some mechanistic constraints which render it unsuitable to produce a stable change in the way we act. What needs to be altered is the distribution itself of the weights or, in other words, the agent's motivational framework. But how could this be done? My suggestion is that a certain kind of attention may contribute to this end, and this is, in my view, the point of Weil's cryptic observation "Exactly the same rule applies to opinions" (sec. 6.6-6.7). The required kind of attention clashes, however, with many assumptions in the Kantian approach, namely, the denial of moral realism, and also with the divided conception of the self. To make room for that kind of attention, I will sketch, in Chapter 4, a defense of a certain sort of moral realism and challenge, in Chapter 5 , the divided conception of the self. Chapter 6 will be reserved for an examination of a certain kind of attention (namely, the one I will refer to as 'passive receptivity') that may allow us to make sense of Weil's remark, and articulate a more appropriate response to harm than the Kantian approach could provide. 


\section{Morality, Self-Knowledge and Human Suffering}

An Essay on the Loss of

Confidence in the World

\section{Josep E. Corbí}


First published 2012

by Routledge

711 Third Avenue, New York, NY 10017

Simultaneously published in the UK

by Routledge

2 Park Square, Milton Park, Abingdon, Oxon OX14 4RN

Routledge is an imprint of the Taylor \& Francis Group, an informa business

(C) 2012 Taylor \& Francis

The right of Josep E. Corbí to be identified as author of this work has been asserted by him in accordance with sections 77 and 78 of the Copyright, Designs and Patents Act 1988.

All rights reserved. No part of this book may be reprinted or reproduced or utilised in any form or by any electronic, mechanical, or other means, now known or hereafter invented, including photocopying and recording, or in any information storage or retrieval system, without permission in writing from the publishers.

Trademark Notice: Product or corporate names may be trademarks or registered trademarks, and are used only for identification and explanation without intent to infringe.

\section{Library of Congress Cataloging-in-Publication Data}

Corbi, Josep E.

Morality, self-knowledge and human suffering : an essay on the loss of confidence in the world / Josep E. Corbi.

p. cm. - (Routledge studies in contemporary philosophy ; 38)

Includes bibliographical references (p. 237) and index.

1. Suffering-Moral and ethical aspects. 2. Civilization, ModernMoral and ethical aspects. 1. Title.

BJ1409.C67 2011

$128.4-\mathrm{dc} 23$

2011045774

ISBN13: 978-0-415-89069-4 (hbk)

ISBN13: 978-0-203-11918-1 (ebk)

Typeset in Sabon

by IBT Global

Printed and bound in the United States of America on sustainably sourced paper by IBT Global. 


\section{Contents}

Acknowledgments $\quad$ xiii

Introduction $\quad 1$

1 Thought Experiments, Justice and Character 11

1.1 John Rawls: The Original Position $\quad 13$

1.2 Primo Levi's Shame 21

1.3 The Kantian Approach 36

2 The Loss of Confidence in the World 45

2.1 The Issue 45

2.2 The Three Poles of Torture 48

2.3 The Content of Our Expectations 52

2.4 The Loss of Confidence in the World as an Irrational Reaction $\quad 58$

2.5 The Realm of Reasons and the Faustian Ideal 61

2.6 Distance and Kinds of Awareness 64

2.7 The Moral Reversal of Time $\quad 69$

2.8 To Close: A Necessary Illusion 71

3 The Real and the Imaginary in the Soldier's Experience 74

3.1 An Initial Approximation 74

$\begin{array}{ll}3.2 \text { The Departure } & 76\end{array}$

$\begin{array}{ll}3.3 \text { The Battlefield } & 81\end{array}$

3.4. The Homecoming 84

3.5 Expressive Awareness and the Matching Assumption 87

4 The Reality of Moral Features 92

4.1 The Need of a Response $\quad 92$ 
4.2 Moral Projectivism and the Bipartite Picture 95

4.3 A Narrative Discipline 98

4.4 Response-Dependent Properties 101

$\begin{array}{ll}\text { 4.5 Procedural vs. Substantive Realism } & 107\end{array}$

4.6 The Moral Law 109

4.7 The Space of Public Reasons 114

5 Moral Principles and the Divided Conception of the Self . 120

5.1 Narrative Discipline and the Perplexities of Disagreement 121

5.2 Moral Principles and the Divided Conception of the Self 128

5.3 Character and Moral Principles $\quad 133$

5.4 Guilt, Principles and Morality 137

5.5 Inner Figures and the Global Attack : 142

5.6 Inner Figures and the Human World 148

6 Self-Knowledge in the Light of a Dance 156

6.1 The Issue 156

6.2 The Deliberative and the Theoretical Attitudes 159

6.3 The Transparency Condition 162

6.4 Avowals and the Goal of Psychoanalytic Treatment 165

6.5 The Notion of Acknowledgment 169

6.6 'Being Forced To' 172

6.7 Receptive Passivity and Double Permeability 174

6.8 Receptive Passivity and the Experience of Dancing 178

6.9 Expression, Inner Figures and Psychic Health 181

7 Conclusion

$\begin{array}{ll}7.1 \text { The Moral Question } & 187\end{array}$

7.2 The Divided Conception of the Self 189

7.3 The Frailty of Principles . 194

7.4 Expressive Awareness and the Three Poles of Harm 197

Notes $\quad 207$

References $\quad 237$

Index 245 